\title{
Design of Solid State Tesla Coil Using 555 Timer and IRFP460N MOSFET
}

\author{
Soumyadeep Sarkar \\ Department of Electrical and Electronic Engineering (EEE), Kurukshetra University, Kurukshetra
}

\begin{abstract}
The Solid State Tesla Coil is a device which is capable of producing extremely high voltage, high frequency and low amperage alternating current electricity. The original device i.e. the Spark Gap Tesla Coil was designed by Nikola Tesla around 1891. This device has similarities to that of a traditional Spark Gap Tesla Coil but has a different circuitry for operation. This paper documents the design, operation and construction of such a system.
\end{abstract}

Keywords: Tesla Coil; Solid State Tesla Coil; Magnifying Transmitter; 555 Timer IC; MOSFET; High Voltage; High Frequency; Corona Discharge.

\section{Introduction}

A Tesla coil is an electrical resonant transformer circuit used to produce high-voltage, low-current, and high frequency alternating current electricity. Nikola Tesla experimented with a number of different configurations of resonant electric circuits. Tesla used these coils to conduct experiments related to electrical lighting, phosphorescence, $\mathrm{X}$-ray generation, high frequency alternating current phenomena, electrotherapy, the transmission of electrical energy without wires, etc. Tesla coil circuits were commercially used in spark-gap radio transmitters for wireless telegraphy until the 1920s, and in medical equipment such as electrotherapy and violet ray devices. Today their main use is for entertainment and educational displays, though small coils are still used today as leak detectors for high vacuum systems.

The Tesla coil was invented around 1891. The original intention for its invention was to create a wireless electrical energy distribution system. Unfortunately, the design could not send power at even close to reasonable efficiency, as almost all the useful power was being wasted on corona and arcing. But what makes the Tesla coil truly magnificent is the voltage it produces. A typical spark gap type coil takes (usually) the voltage from a common wall socket, and steps it up to a couple thousand volts, where it then goes through the switching circuit, through the primary, and is seen on the secondary side as more than 200,000 volts. This type of Tesla Coil requires a high voltage supply. A Solid State Tesla Coil does not require this, as it works with mains voltage.

The Solid State Tesla Coil is one of the types of Tesla coils available. It has several advantages over the more common spark-gap Tesla coil. They are less noisy than conventional Tesla coils, yet they can still achieve a respectable output. They can also be made to play music through its spark, which is Audio Modulated. They are also friendlier to nearby electronic apparatus, though one should still be cautious. Its main component, the 555 timer IC is connected to the circuit and the supplied power is 12 Volts, 500 mili-amperes, the MOSFET used is the IRFP460N. The MOSFET (with a 680 picofarad, 2 Kilo-volt capacitor) is connected to one end of the primary coil and the other is connected to one end of the 110 Volts AC line with a 6 Ampere diode in series. The MOSFET is protected using several diodes on the Gate, Drain and Source pins. The capacitor which is used in parallel with the AC line is a Mylar capacitor; FKPs and MKPs can also be used. Such capacitors are used because first, the ordinary capacitors may not work and second, due to the load of the device. The Secondary coil is made using pure copper wire of 36 American Wire Gauge with additional spray varnishing insulation coating to prevent leakage. One end of the Secondary coil is grounded and the other is connected to a toroid for top load capacitance, the expression of which is given by:

$$
\mathrm{C}=1.4\left(1.2781-\frac{D_{2}}{D_{1}}\right) \sqrt{\pi\left(D_{1}-D_{2}\right) D_{2}}
$$

where, $\quad \mathrm{C}=$ Top-load Capacitance.

D1= Diameter of the Toroid Ring.

D2= Diametric Thickness of the Ring.

Its Spark Length can be calculated by:

$$
\mathrm{L}=1.7 \sqrt{\mathrm{P}}
$$

where, $\quad \mathrm{P}=$ Power.

$\mathrm{L}=$ Spark Length.

And for matching the Inductance to the capacitance for proper resonance frequency, the expression is given by:

$$
F=\frac{1}{2 \pi \sqrt{L C}}
$$

where, $\mathrm{F}=$ Resonant Frequency $(\mathrm{KHz})$

$\mathrm{L}=$ Inductance. $(\mathrm{mH})$

$\mathrm{C}=$ Capacitance (microfarads)

The coil is tuned to the best of my knowledge and the best configuration which is used is:

\section{A. For Primary Coil:-}

$2 \mathrm{~mm}$ insulated wire with $1 \mathrm{~mm}$ insulation and $1 \mathrm{~mm}$ wire wound on a PVC pipe of $9 \mathrm{~cm}$ diameter with 15 turns. 


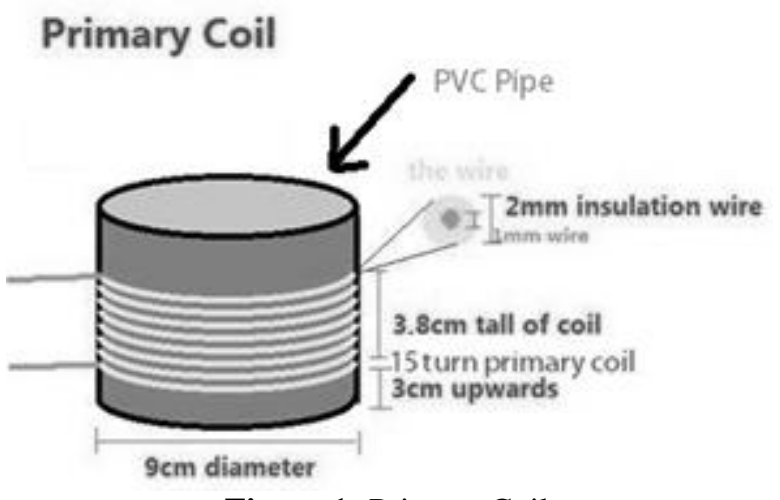

Figure 1: Primary Coil

\section{B. For Secondary Coil}

36 American Wire Gauge copper wire wound on a PVC pipe of $6 \mathrm{~cm}$ diameter and $20 \mathrm{~cm}$ in height with $18.5 \mathrm{~cm}$ of winding, leaving free space of $0.75 \mathrm{~cm}$ on both the sides.

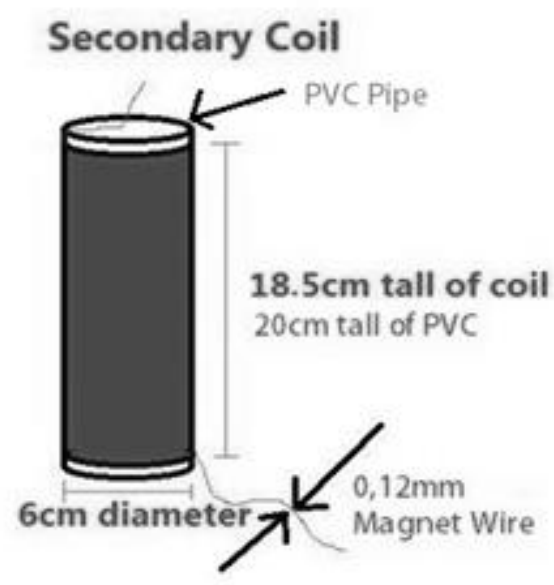

Figure 2: Secondary Coil

\section{555 Timer Circuit}

The 555 timer IC (also known as the "Time Machine" of an electronic circuitry) is an integrated circuit (chip) having a variety of uses as a timer, flip-flop element, pulse generator or even in oscillator applications. The 555 can be used to provide time delays, as an oscillator, and as a flip-flop element. Certain IC derivatives can provide up to four timing circuits in one package.

It was designed by an American Company named Signetics in the year 1971 and is still in widespread use because of its affordability and device stability.

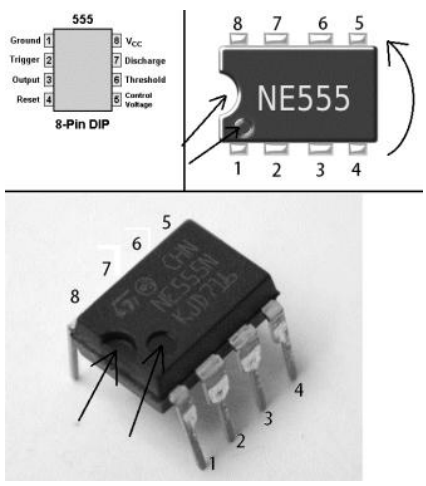

Figure 3: NE555 Chip

\section{The MOSFET}

The Metal Oxide Semiconductor Field Effect Transistor or a MOSFET is a type of transistor used for amplifying, modulating and switching electronic signals. The MOSFET is actually a four terminal device with Source (S), Gate (G) and Drain (D) and the Body (B) terminals; with the body internally connected to the Source making it a three terminal device.

The main advantage of using a MOSFET over an ordinary transistor is that it requires very little current to turn on, while delivering a much higher current to a load. However it requires a higher gate voltage to turn on.

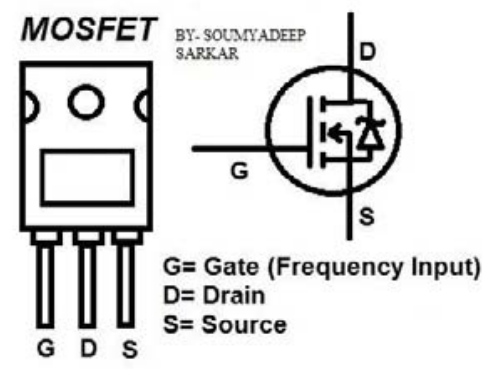

Figure 4: IRFP460N

\section{Tuning The Tesla Coil}

Proper tuning is essential for achieving good power output from the SSTC. The resonator is a high-Q RLC circuit. If it is not driven at the correct frequency, the driver will see it as a high-impedance reactive load. More importantly, proper tuning provides major efficiency benefits.

The most important is its tuning both the Primary Coil and Secondary Coils. There are various ways of tuning the coil but a basic way of doing it is to make certain that the Primary Coil's resonant frequency is tuned to that of Secondary coil, by using low power oscillations and then increasing and decreasing it accordingly until maximum power is obtained.

\section{Advantages of Solid State Tesla Coil Over Traditional Spark Gap Tesla Coil}

The most basic advantage which a Solid State Tesla Coil has over the traditional Tesla Coil is that the analysis of its circuitry is very (using circuit theory).They are also very easy to set up whereas the traditional spark gap Tesla coil requires high drive voltage for good sparks. The SSTC is flexible in terms of impedance matching. The traditional Tesla Coil also needs a high voltage power source which is usually derived from Neon Sign Transformers or Microwave Oven Transformers but the Solid State Tesla Coil does not need any such kind of power source. An additional problem with the traditional Tesla Coil is the complex tuning procedure, needed to achieve optimal performance.

\section{Pictorial Representation of the Solid State Tesla Coil Working at Maximum Power}

Here we can see the Solid State Tesla Coil working in its best configuration. High voltage corona arching can also be seen on the top of the coil.

\section{Volume 5 Issue 10, October 2016 www.ijsr.net}


International Journal of Science and Research (IJSR)

ISSN (Online): 2319-7064

Index Copernicus Value (2013): 6.14 | Impact Factor (2015): 6.391

Note: Here the coil is working without the placing of a Top Load Capacitance.

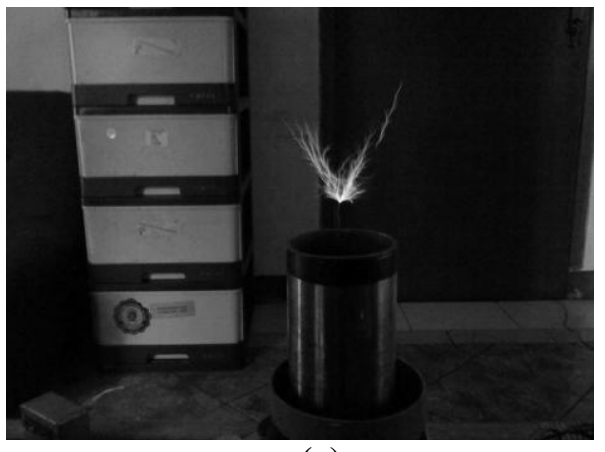

(a)

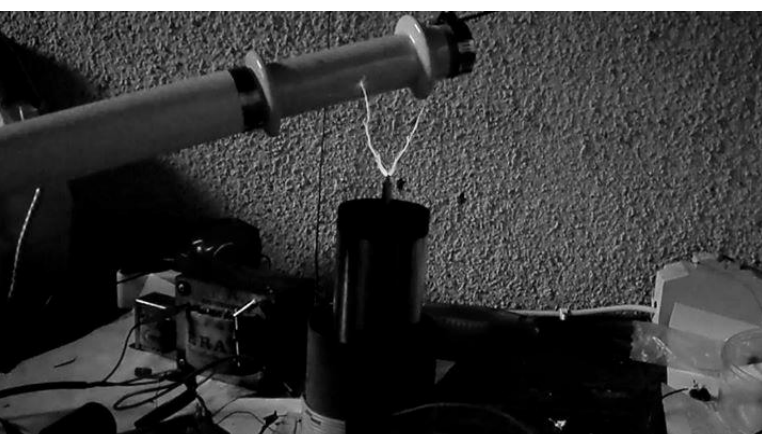

(b)

Figure 6: (a), (b) Maximum Power Performance.

\section{Installation Diagram}

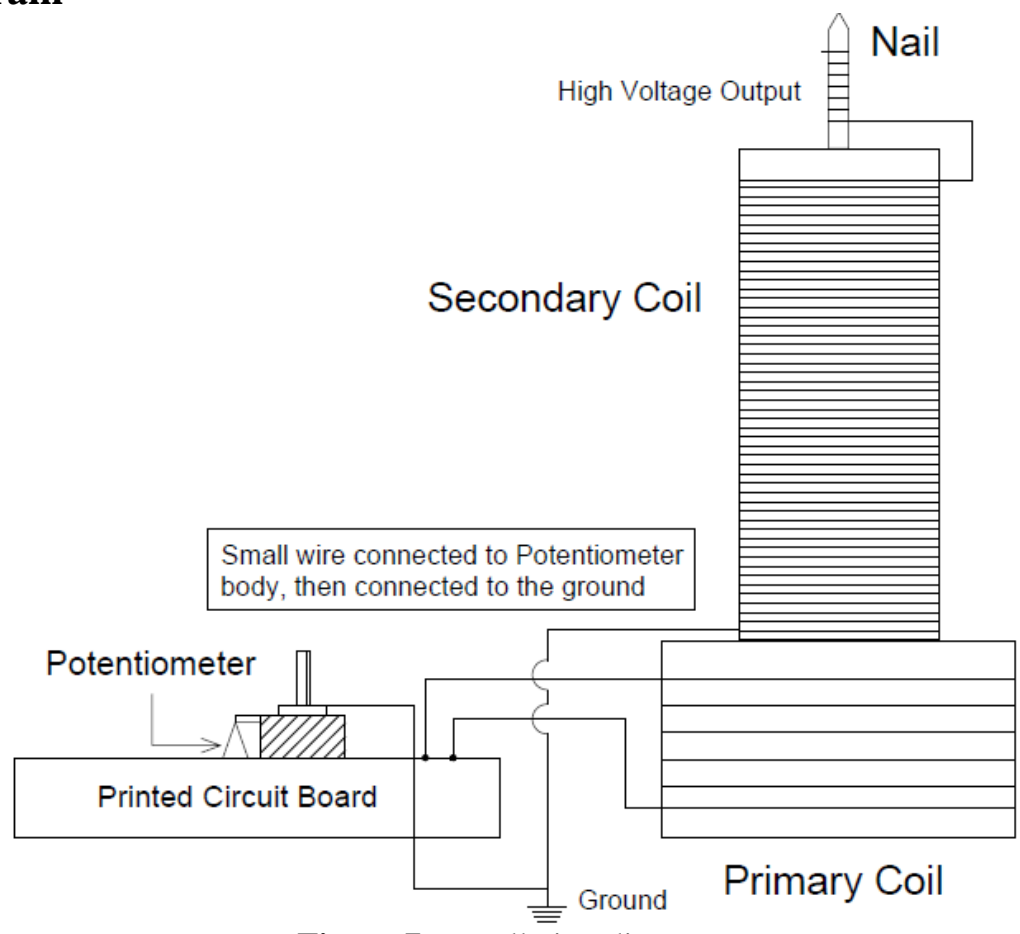

Figure 7: Installation diagram

\section{The Schematic}

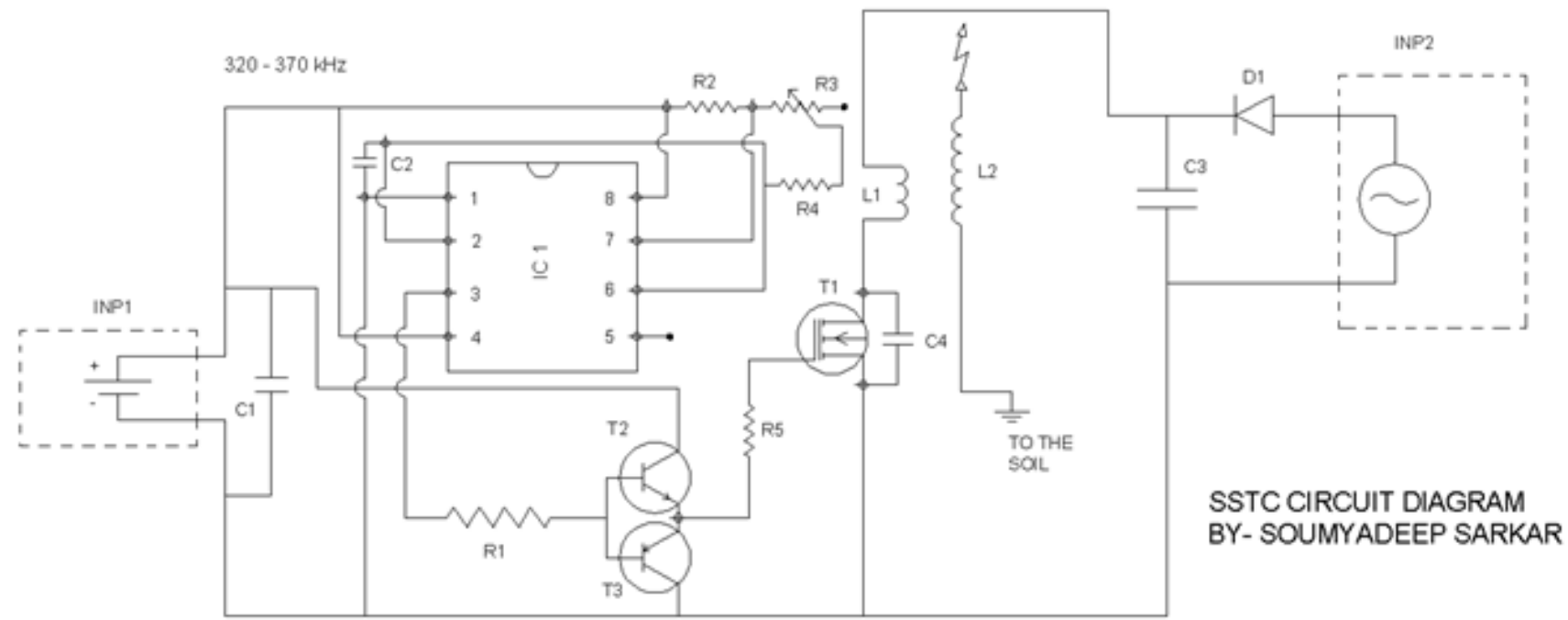

Figure 8: Circuit Diagram

Volume 5 Issue 10, October 2016

www.ijsr.net

Licensed Under Creative Commons Attribution CC BY 


\section{International Journal of Science and Research (IJSR) \\ ISSN (Online): 2319-7064}

Index Copernicus Value (2013): 6.14 | Impact Factor (2015): 6.391

\section{List of Components}

to build the proposed Solid State Tesla Coil circuit:

The following table provides a list of components necessary

Table 1: Component List

\begin{tabular}{|c|c|c|c|c|}
\hline \multicolumn{5}{|c|}{ COMPONENT LIST FOR SSTC CIRCUIT } \\
\hline S. No. & Component & Component Type & Values & Comments \\
\hline 1. & R1 & Resistor & $270 \Omega$ & \\
\hline 2. & $\mathrm{R} 2$ & Resistor & $1 \mathrm{k} \Omega$ & Min. 5 Watt \\
\hline 3. & R3 & Potentiometer & $1-5 \mathrm{k} \Omega$ & \\
\hline 4. & R4 & Resistor & $6.4 \mathrm{k} \Omega$ & \\
\hline 5. & R5 & Resistor & $10 \Omega$ & Min. 5 Watt \\
\hline 6. & $\mathrm{C} 1$ & Capacitor & $1000 \mu \mathrm{F}, 16 \mathrm{~V}$ & \\
\hline 7. & $\mathrm{C} 2$ & Capacitor & $330 \mathrm{pF}$ & \\
\hline 8. & $\mathrm{C} 3$ & Capacitor & $470-1000 \mathrm{nF}, 275-400 \mathrm{~V}$ & MKP/ FKP/ MYLAR \\
\hline 9. & $\mathrm{C} 4$ & Capacitor & $680 \mathrm{pF}, 2 \mathrm{kV}$ & \\
\hline 10. & $\mathrm{~T} 1$ & MOSFET & IRFP460N & \\
\hline 11. & $\mathrm{~T} 2$ & Transistor & BD139 & \\
\hline 12. & T3 & Transistor & BD140 & \\
\hline 13. & IC1 & NE555 IC Chip & & \\
\hline 14. & D1 & Diode & $6 \mathrm{~A}$ & \\
\hline 15. & INP1 & Input System & $12 \mathrm{VDC}, 500 \mathrm{~mA}$ & Pure DC \\
\hline 16. & INP2 & Second Input System & 110V AC (max.) & \\
\hline
\end{tabular}

\section{The Method of Driving the Primary Coil of the Solid State Tesla Coil}

The Tesla Coil is driven by a primary coil that is coupled to a resonator. Energy is transferred from the primary coil to the secondary coil (resonator) by means of magnetic coupling between them. When the drive method is employed we also benefit from the "step-up" of the drive voltage due to transformer action between the two coils. The SSTC described in this report can be controlled by a function generator, adjusting its operating frequency is as simple as turning a knob- the potentiometer knob in the circuit.

\section{Applications}

The concept of using a Tesla coil to power high voltage devices is not at all new. In the early 1900s, it was commonly used by scientists to drive X-ray and gas filled tubes. This setup fell into disfavour not because of limitations of the air core transformer, but because of the impracticality of the spark gap. Spark gaps produce broadband radio emissions that interfere with radios at a significant distance.

The SSTC partially solves this problem. The electromagnetic emission of the SSTC has a very narrow bandwidth, and does not seem to cause major interference with commercial radio equipment. In terms of potential electromagnetic interference, the SSTC is very similar to the $\mathrm{RF}$ induction furnace, which operates at up to $400 \mathrm{KHz}$ and is commonly found in industrial plants. Induction chargers are also able to drive air core coils without causing major radio interference. The electromagnetic emission of the SSTC must be considered, but is probably not prohibitive.

The traditional Tesla coil has other commercial disadvantages as well. The spark gap is an inefficient switch, and the wasted energy is not dissipated in the form of benign heat. Spark gaps can produce loud noises, UV radiation, ozone, and other hazards. In contrast, the H-bridge driver is very efficient. It is also much more reliable than a spark gap.

The most important benefit of the SSTC is its continuous wave output. Since the oscillator of a traditional Tesla coil needs to be recharged, it provides pulsed output power. The SSTC output is a clean sine wave.

An additional problem with the traditional Tesla coil is the complex tuning procedure needed to achieve optimal performance. If two LRC resonant circuits are used, one of them must be tuned to match the other. This is achieved by tapping the primary coil at the correct point.

Since the SSTC described in this report is controlled by a function generator, adjusting its operating frequency is as simple as turning a knob.

\section{Conclusion}

Although the traditional Tesla coil has been removed from most commercial applications outside of the special effects industry, the SSTC may prove to be a much more practical device. The air core transformer described here uses only 36AWG magnet wire, and is much cheaper than a comparable ferrite transformer. The circuit is also fairly

\section{Volume 5 Issue 10, October 2016}


inexpensive to construct. Like the traditional Tesla coil, the SSTC can be used as a power supply for UV lamps, X-ray tubes, and other high voltage components. It can perform the operation without introducing the disadvantages of a spark gap.

Nikola Tesla, the person who electrified the world has predicted that the world is destined to be running on only one source of energy, i.e. electricity. With the traditional version of this device he tried to send energy, electrical energy to all people for free. However, to his dismay he found that the device is wasting energy in the form of arching and corona discharging, with a little modification on the device he could have made his design successful which he couldn't, not because of certain circumstances. I believe, this device is the key to the future. He also presented the fact that earth's crust is a conductor of electricity, if by any means, we can convert the crust in to a conductor, which covers the whole earth, it would provide electricity without the use of wires to any part of the world.

Electricity and Magnetism are unique forces in nature. They have a strange effect upon one another, very stimulating and exciting. If we achieve the power of manipulating them at a certain procedure, it would probably change the world.

The Tesla Coil as we know today is based on unfinished technology. Nikola Tesla designed those coils, believing them to be the stepping stones to something greatersomething so big, that it would kick off an energy race which would dwarf the nuclear race. The future iteration of this device uses more sophisticated solution. A phase locked loop is used to adjust the operating frequency until the primary current is in phase with the secondary voltage. Such systems are still being developed.

\section{References}

[1] "Tesla Coil- Wikipedia, the free encyclopaedia", Available: https://en.wikipedia.org/wiki/Tesla_coil

[2] "Solid State Tesla Coil and their Uses by Sean Soleyman (14 December, 2012)", Available: http://www.eecs.berkeley.edu/Pubs/TechRpts/2012/EE CS-2012-265.html

[3] "Class E- A New Class of High Efficiency Tuned Single Ended Switching Power

Amplifiers," IEEE Journal of Solid State Circuits (Vols. SC-10, no. 3, 1975).

[4] R.Burnett, https://www.richieburnett.co.uk/sState2.html

[5] R. C. Weast, CRC Handbook of Chemistry and Physics, 62nd, CRC Press, Inc, 1981.

[6] L. Balogh, ": Design and Application Guide for High Speed MOSFET Gate Drive Circuits", Available: http://www.ti.com/lit/ml/slup169/slup169.pdf

[7] Chakrabarti, "Circuit Theory, Analysis and Synthesis", $\begin{array}{llll}\text { Dhanpat Rai \& } & \text { Co. }\end{array}$ Ltd., RP2012

[8] Robert L. Boylestad- Louis Nashelsky, "Electronic Devices and Circuit Theory", Tenth Edition, Pearson.

[9] Abdul Hadi's Solid State Tesla Coil. 